\title{
Experimental study of mechanical properties of steel cables
}

\author{
Renata Orzłowska ${ }^{1, *}$ \\ ${ }^{1}$ Koszalin University of Technology, Faculty of Civil Engineering, Environmental and Geodetic \\ Sciences, Śniadeckich 2 St. 75-453 Koszalin, Poland
}

\begin{abstract}
Guyed masts are structures particularly sensitive to various types of nonlinarities. Static calculations of masts should be performed in accordance with EN 1993-3-1 using global elastic analysis. This is justified in the case of pre-stretched cables on mast guys, characterized by a constant value of the modulus of elasticity. In the case of non-stretched cables this approach is inappropriate, because permanent rope elongations caused by the applied load can significantly reduce the stiffness of the mast. The paper presents the preparation process of rope samples for experimental tests and preliminary results of tests aimed at determining the actual stress - strain relation of the rope and estimation a constant elastic modulus $E$ of the cable after a few cycles of loading and unloading. The results of the obtained tests are introductory to further numerical analysis of guyed masts, including physical nonlinearity of guys.
\end{abstract}

\section{Introduction}

In engineering practice a constant value of elastic modulus $E$ for cables is taken into account in order to calculate guyed masts. This approach is correct in the case of prestretched cables on mast guys. It happens, however, that despite the constant modulus of elasticity assumed in calculations, new, non-stretched cables are used to build the guyed masts. This solution may constitute a serious factual error. Brand new cables are characterized by a non-linear stress - strain characteristic $\sigma-\varepsilon$, therefore the variable elastic modulus depends on current stresses level and may be less (even by $30 \%$ ) [1,2] than the constant value of $E$ [3]. This issue acts directly on the stiffness of mast elastic supports and may produce permanent strains corresponding to the mast non-vertical position. Therefore the computations should consider actual mechanical properties of non-stretched cables, determined on the basis of experimental static tensile test results [4]. The paper presents a detailed process of preparing samples of a certain steel rope for tests. The research methods in this field and the standard requirements are also discussed. The results of the research will be used directly to analyze guyed masts in the light of physical nonlinearity.

\footnotetext{
${ }^{*}$ Corresponding author: renata.orzlowska@tu.koszalin.pl
} 


\section{Purpose and scope of the experimental research}

The experimental research was conducted on a spiral strand rope - type $1 \times 37$ of diameter equal $20.1 \mathrm{~mm}$ and a minimal breaking force equal $367 \mathrm{kN}$, stated by the manufacturer [5,6] (Fig.1).

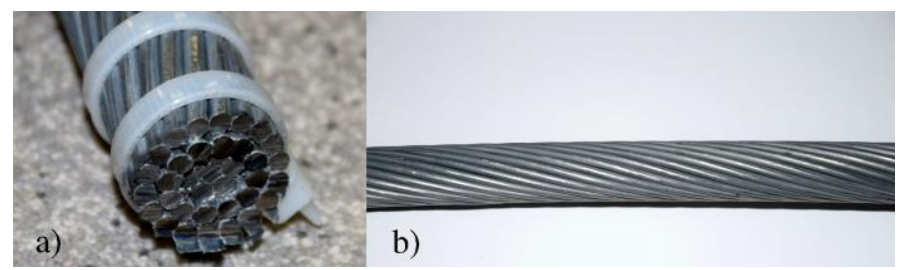

Fig. 1. Rope accepted for the research: a) cross section, b) view of the tested rope.

The scope of the research included:

- Determination of the stress - strain characteristic during static tensile test based on measured values: force - elongation of cable,

- Finding the constant elastic modulus $E$ of cable after a few cycles of loading and unloading,

- Determination of the real value of a cable breaking force.

\section{Preparation of the cable samples to research}

The current standard regulations [7] present recommendations for the cable samples to conform in a research, concerning the determination of the real value of a cable breaking force. In the case of spiral strand ropes, the minimal length of a sample depends on its nominal diameter, it should be equal $1000 \mathrm{~mm}$, disregarding the rope termination at both ends. They should be anchored to make the anchorage resistance at least equal to the resistance of an anchored cable (Table 1).

Table 1. The minimal length of a cable sample without anchorages.

\begin{tabular}{|c|c|c|c|c|}
\hline $\begin{array}{c}\text { Nominal diameter of cable } \\
(\mathbf{m m})\end{array}$ & $\mathrm{d} \leq 6$ & $6<\mathrm{d} \leq 20$ & $20<\mathrm{d} \leq 60$ & $\mathrm{~d}>60$ \\
\hline $\begin{array}{c}\text { Minimal length of spiral } \\
\text { strand rope (mm) }\end{array}$ & 500 & 1000 & $50 \mathrm{xd}$ & 3000 \\
\hline
\end{tabular}

Due to the possibility of placing a cable sample in a tensile test machine, an anchorage in the form of a conical bush using socketing was selected. The minimal dimensions of the conical bush based on guidelines [1,8] are shown in Fig. 2.

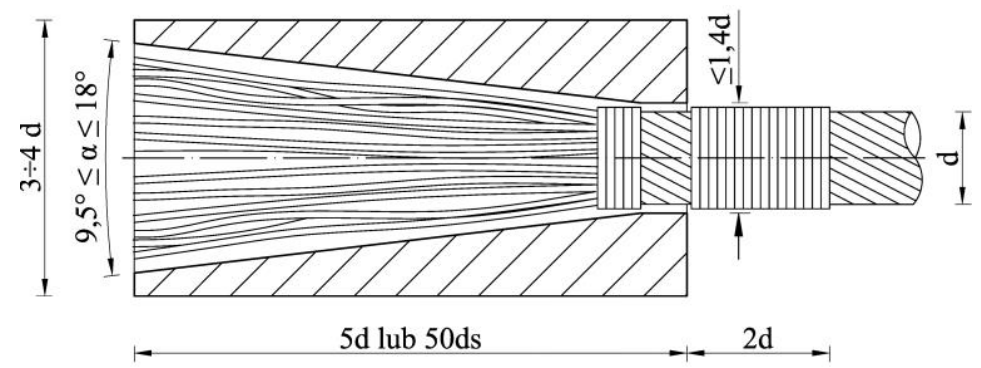

Fig. 2. Minimal dimensions of the conical bush. 
According to [9], the width of the hole should be at least $1.2 \mathrm{~d}+3 \mathrm{~mm}$. Fig. 3, shows geometrical dimensions of the samples prepared to the tests.

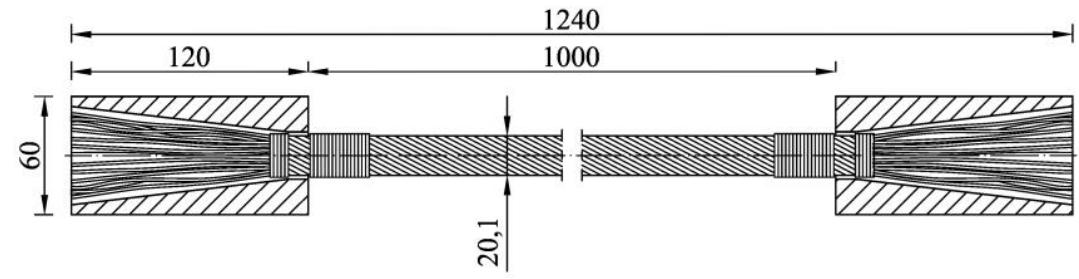

Fig. 3. Dimensions of cable sample to tests.

The conical bushes, anchoring the cable section prepared to tests were made of 355 steel grade. The original cold socketing compound named WIRELOCK (resin for conical sockets) was used as a socketing media. The preparation process of cable sample anchorage was performed according to the standard guidelines [8] and recommendations of the resin manufacturer's instructions [10]. After measuring and marking the length of a cable section to cut, separate sections on both ends should be secured to prevent their unlaying. For this purpose the serving bands were used. Before placing the cable in the bush it is necessary to perform the primary serving - best from a soft annealed iron wire of small diameter. In accordance with [10], primary serving should be applied at distance equal to the length of the bush basket, measured from the cable end and must be at least twice as wide as the minimal diameter of the rope. In order to unlay the end of the cable, one should pull the cable through the conical bush, remove the secondary servings at the end of the cable and unlay individual wires in such a manner that the ending of the cable would resemble a broom. In accordance with [8], the spreading angle should not be wider than $45^{\circ}$ from the vertical axis of the cable, while according to the resin manufacturer's instructions [10], this angle should be limited to 30 degrees. Once the wires are bent they should be cleaned from grease and dirt. Before placing the broom into the bush, the wires should be completely dry. The conical bush should be put on the broom, in such a way that the base of the broom sticks out of the bush no more than half of the minimal diameter of the cable. It is very important to evenly distribute the wires in the bush basket.

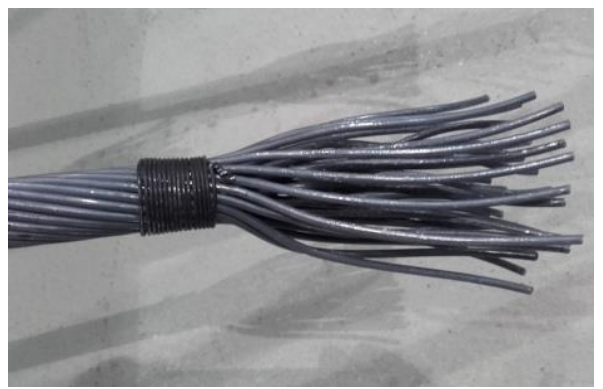

Fig. 4. Unlaying of the spiral strand rope into individual wires.

According to [8], collinearity of the clamp rope should be ensured in relation to the bush on length equal three coils of cable. This length can be reduced by means of appropriate clamps. The bush should be secured before changing the location. The rope end in the form of a broom and the bush should be placed vertically in one axis. It is necessary to properly seal the hole of the bush prior to socketing (the resin should not be allowed to leak out). In accordance to [10], putty or plasticine should be used for sealing. The rope termination prepared this way is ready for socketing. 


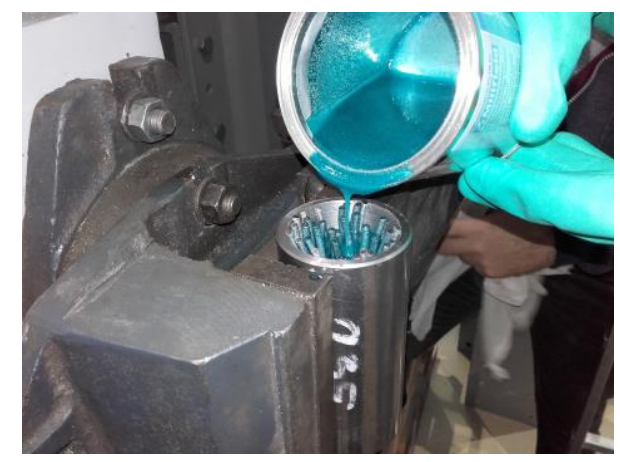

Fig. 5. The socketing of rope termination using WIRELOCK resin.

The procedure of conical bush socketing using WIRELOCK resin was done according to $[8,10]$. In order to do so, the two-containers socketing compound, consisting of polyester resin and granular compound in WIRELOCK technology were used in the tests. After mixing both components a chemical process, which begins a curing process of resin takes place. According to [10], mixing of all contents from both containers of the individual kit is required. After pouring all of the resin to the container with granular compound, one should thoroughly mix them for at least 120 second using a flat wooden paddle. After obtaining a homogeneous consistency of the mixture, one should slowly pour it into the conical bush until it is completely filled. It is especially important to maintain a sufficiently low pouring speed due to the possibility of the occurrence of air bubbles, which reduce the strength properties of resin. The socketing material should be appropriately fluid, in order to efficiently penetrate into any narrow crevices. During socketing, any leakage of resin from the conical bush should be carefully observed. In the case of leaks, it is required to stop them as well as to refill the resin loss in the conical bush. The bonding speed depends on the air temperature during socketing. The WIRELOCK resin congeals within 15 minutes at the temperature of $18^{\circ} \mathrm{C}$ to $24^{\circ} \mathrm{C}$. An increase in temperature by $10^{\circ} \mathrm{C}$ shortens the gelling time by approximately $50 \%$, in turn a decrease in temperature by $10^{\circ} \mathrm{C}$ lengthens the gelling time by approximately $100 \%$. Rope termination should be motionless until it is possible to perform a scratch test, which involves scratching with a sharp object over the surface of the resin. The result of this test is accepted only if not more than a thin, bright-colored crack is visible on the surface. Before testing, the sealing material securing the resin from leaks must be removed from the bush. The resin component in the original phase, after mixing the ingredients occurs in the form of a dark blue - green liquid. After the curing process it is visible in the form of a bright green compact solid.

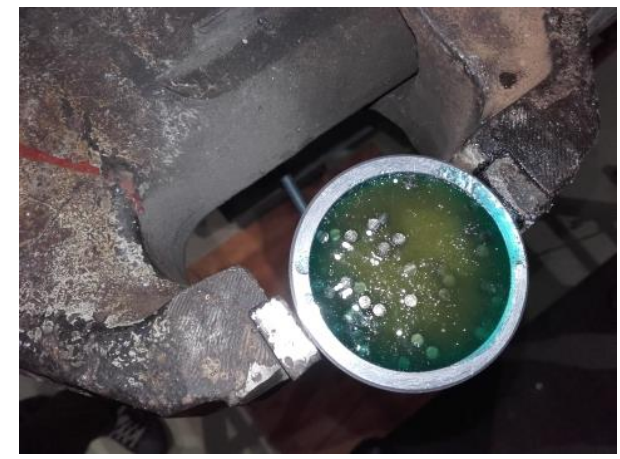

Fig. 6. WIRELOCK resin after the curing process. 


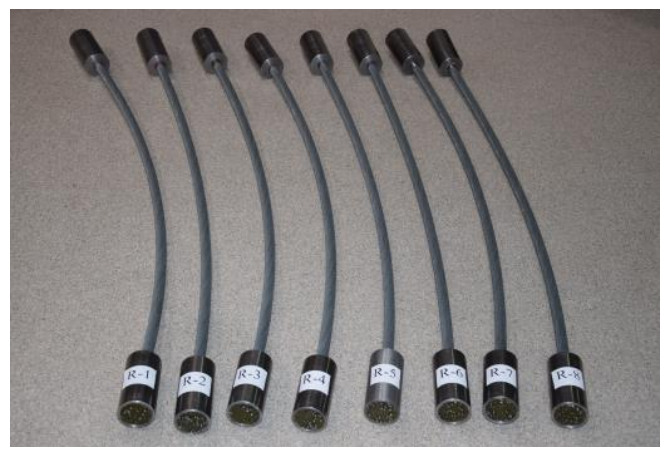

Fig. 7. Preparing the cables sample to tests.

\section{Experimental tests on ropes}

Experimental tests were carried out on the Inspekt 600 testing machine shown in Fig. 8.

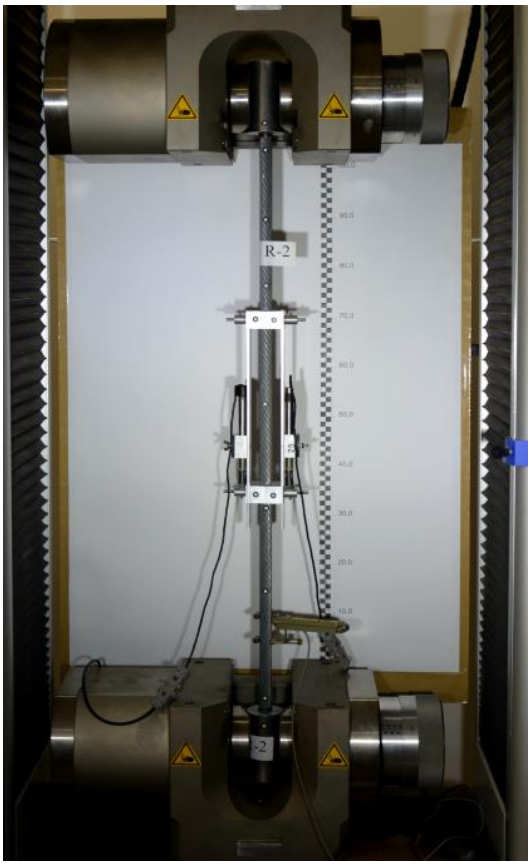

Fig. 8. View of the rope sample in tensile test machine.

First of all, experimental tests of longitudinal strains and elastic modulus of the rope were carried out. According to [11], the pre-stretching process of steel mast guys should be carried out by means of cyclical rope loading and unloading in the range from $10 \%$ to $50 \%$ of the breaking force. The test performance requires at least 10 cycles. The tested rope samples were loaded and unloaded 12 times at a rate of $1 \mathrm{kN} / \mathrm{s}$. In order to eliminate the initial non-straightness, the tested rope sections anchored in the handles of the testing machine should be loaded with a preliminary force. In experimental tests, this value was taken at the level of $10 \mathrm{kN}$. The measurement of the force value from the tensile test machine in the conducted tests was read in a time interval equal to $0.5 \mathrm{~s}$. Regardless of the exact graph of characteristic $\sigma-\varepsilon$ from the testing machine, the elongations of the rope 
samples were additionally measured using two extensometers with a nominal accuracy equal $0.001 \mathrm{~mm}$. A measurement base on length $300 \mathrm{~mm}$ was assumed. Moreover, in order to determine the cable elongation, an optical image correlation system [12] was used. This system allows to measure element displacements produced by loading with the similar accuracy equal to accuracy of extensometers.

\section{Results of experimental tests}

In order to determine the constant value of elasticity modulus $E$ of the cable after its prestretching, the stress-strain characteristic $\sigma-\varepsilon$, shown in Fig. 9 was obtained in experimental tests.

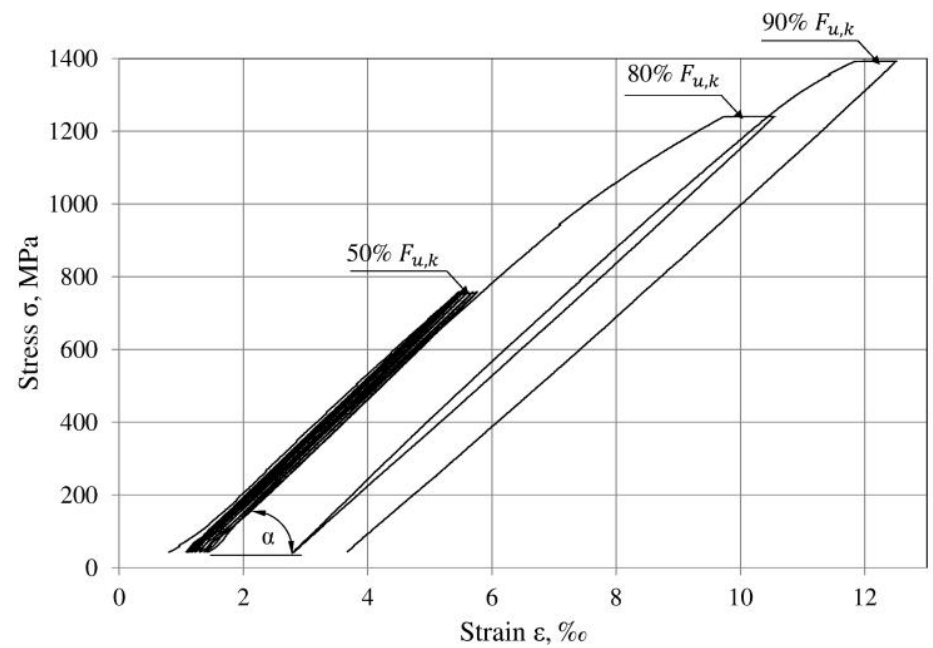

Fig. 9. Graph of non-linear dependence stress-strain during cyclic loading and unloading.

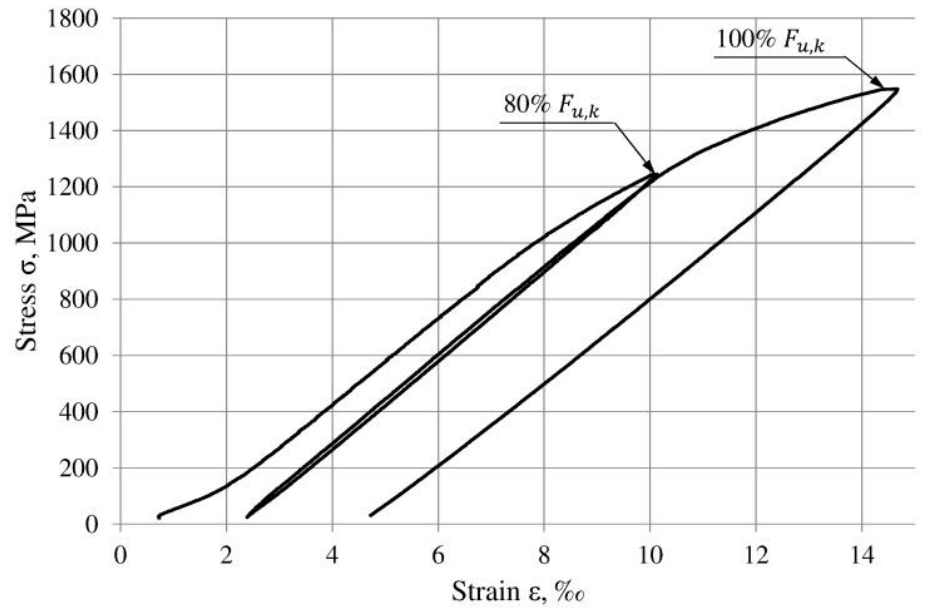

Fig. 10. Graph of stretching the factory rope in two consecutive loading and unloading cycles.

The standard (constant) elasticity modulus $E$ of the cable is referred to as $E=\operatorname{tg}(\alpha)$. The real value of this modulus, determined by the tests after the pre-stretching (twelve times), is equal to $158,28 \mathrm{GPa}$ for the R6 sample. Thus, the above dependence confirms a good compliance of the obtained results (the standard [3], the $E$ material value of the considered 
type of ropes is equal $150 \pm 10 \mathrm{GPa}$ ). It can be observed on Fig. 9 that during the first rope loading, the stress - strain characteristic $\sigma-\varepsilon$ is curvilinear, the curve graphs in the loading and unloading curves differ significantly. A rope, especially a new one, is permanently lengthen in the stretching process as a result of elimination of spaces between twisted wires in the cross section. Repeating loading and unloading of the cable causes its permanent elongations, which has an influence on a significant increase of elasticity modulus $E$. Fig. 10 shows the stress - strain characteristic $\sigma-\varepsilon$, obtained during the static tensile test based on measured values of force - elongation of the rope.

The rope stretching graph (Fig. 10) shows the non-linear dependence of $\sigma-\varepsilon$, of the tested sample under the influence of the applied load equal $80 \%$ of the nominal breaking force (in the first cycle) and 100\% of this force (in the second cycle).

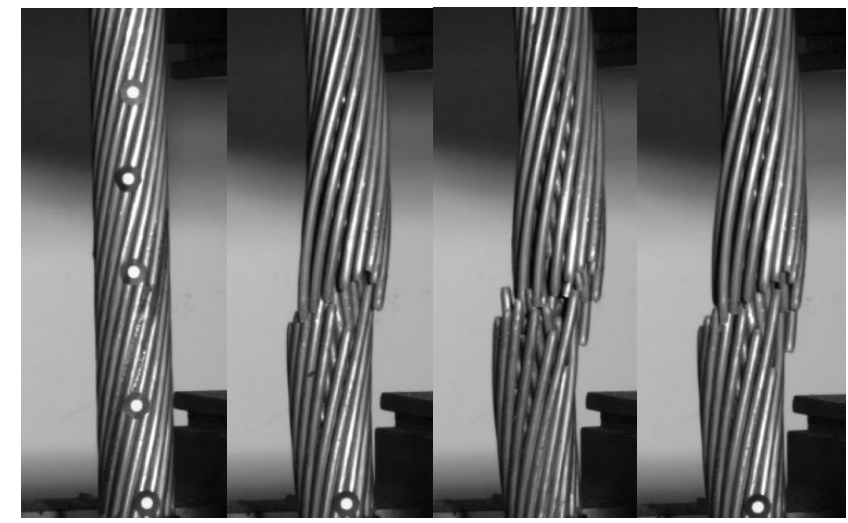

Fig. 11. Stages of destruction of a rope sample in an experimental test of the actual rope breaking force, obtained with the use an optical image correlation system [12].

Fig. 11 presents the process of breaking the sample in the test machine in order to determine the real cable breaking force. In the tensile process, a rope broke while reaching a force equal to $427 \mathrm{kN}$.

\section{Summary}

The paper describes the process of preparing samples of a particular specific steel rope for the experimental tests. The process of socketing the rope terminations with modern WIRELOCK resin guide is precisely described. The use of this technology guarantees high strength and a good adhesion to steel. The socketing process can be conducted in field conditions in the temperature range from $+9^{\circ} \mathrm{C}$ to $43^{\circ} \mathrm{C}$, without a necessity of using any additional improvement. A relatively short time to prepare resin for socketing and achieve full strength in the terrain is a great advantage. For this reason, the above-mentioned technology is increasingly used in industry and civil engineering around the world. The results obtained from the research concerning determination of the standard modulus value of rope deformation after initial pre-stretching, are similar to those provided by the rope manufacturer [5]. Comparing the obtained value of the modulus equal 158,28 GPa, it can be seen that it is range of the value assumed in the design computations $(160 \pm 10 \mathrm{GPa}-$ manufacturer's data, $150 \pm 10 \mathrm{GPa}$ - standard [3]).

The actual breaking force of a cable with value $427 \mathrm{kN}$ is greater than the nominal breaking force specified by the manufacturer $(367 \mathrm{kN})$. The non-linear dependence of $\sigma-\varepsilon$ of the tested rope sample, obtained during the static tensile test, is a characteristic of nonstretched cable. In this case, correct determination of standard elastic modulus of the cable must refer to a specific cable load level and it is therefore a variable value. It should be 
noted that experimental studies have not been completed. The results of the obtained tests are preliminary for a further numerical analysis of guyed mast structures, including physical nonlinearity of the guys.

\section{Acknowledgements}

I would like to express my sincere thanks to Mr. John Dodd (Millfield Wirelock) and Mr. Daniel Jacheć (PFEIFER SEIL - UND HEBETECHNIK GMBH) for the support and financial assistance that contributed to carrying out the presented research. I want to express my appreciation and thanks to SANGER METAL Sp. z o. o. for valuable instructions and technical support.

\section{References}

1. M. Matuszkiewicz, Static analysis of cable structures in elasto-plastic range, Doctoral dissertation, Koszalin University of Technology (2001) [in Polish]

2. Sz. Pałkowski, Cable structures, WNT (1994) [in Polish]

3. Eurocode 3: Design of steel structures - Part 1-11: Design of structures with tension components (2008) [in Polish]

4. J. Hankus, GIG, Structure and mechanical properties of steel ropes (1990), [in Polish]

5. Pfeifer Seil -und Hebetechnik GmbH, Pfeifer Tension Members (2015)

6. PN-EN 12385-10+A1: Steel wire ropes - Safety - Part 10: Spiral ropes for general structural applications (2008) [in Polish]

7. PN-EN 12385-1+A1: Steel wire ropes - Safety - Part 1: General requirements (2009) [in Polish]

8. PN-EN 13411-4: Terminations for steel wire ropes - Safety - Part 4: Metal and resin socketing (2011)

9. K. Feyrer, Springer-Verlag Berlin Heidelberg New York, Drahtseile. Bemessung, Betrieb, Sicherheit (1994)

10. Millfield Enterprises (Manufacturing) Limited, WIRELOCK. Technical data manual (2017)

11. Eurocode 3: Design of steel structures - Part 3-1: Towers, masts and chimneys Towers and masts (2008) [in Polish]

12. GOM GmbH Brauschweig, PONTOS User Manual (2011) 